\title{
Co-Infections Increase the Risk of Pregnancy Outcomes
}

\author{
Alsamarai AM1,2*, Aljumaili ZKM1,3 and Alobaidi $\mathrm{AH}^{4}$ \\ ${ }^{1}$ Departments of Microbiology and Medicine, Tikrit University College of Medicine, \\ Tikrit, Iraq \\ ${ }^{2}$ Faculty of Medicine, Aalborg Academy of Science, Denmark \\ ${ }^{3}$ Kirkuk Health Authority, Kirkuk, Iraq \\ ${ }^{4}$ Kirkuk University College of Veterinary Medicine, Kirkuk, Iraq
}

\section{Research Article \\ Volume 2 Issue 11}

Received Date: November 05, 2018

Published Date: November 29, 2018

DOI: $10.23880 /$ vij-16000201

*Corresponding author: Abdulghani Mohamed Alsamarai, Departments of Microbiology and Medicine, Tikrit University College of Medicine, Tikrit, Iraq, Faculty of Medicine, Aalborg Academy of Science, Denmark, Email: galsamarrai@yahoo.com/abdulghani.Mohamed@tu.edu.iq

\section{Abstract}

Background: Infectious pathogens are one of the causal agents for secondary immunosupression and acquired immunosupression due to pathogens is primarily caused by viruses that invade the cellular compartment of the immune system.

Aim: To determine whether co-infection of TORCH complex agents increased the development of bad obstetric outcome.

Patients and methods: The total number of women included in the study was 538, of them 293 (54.5\%) were with BOH, and 245 (45.5\%) were with normal pregnancy history. In the BOH group, 144 (49.1\%) women were pregnant, while in the normal pregnancy group, 117 (47.7\%) were pregnant. IgG and IgM antibodies were detected in sera of all groups using ELISA method.

Results: There was a significant frequency difference in seroprevalence of T. gondii, rubella and CMV IgG as indication of co-infection between pregnant $\mathrm{BOH}$, non-pregnant $\mathrm{BOH}$, pregnant normal, and non-pregnant normal. Rubella and CMV co-infections were significantly higher in women with $\mathrm{BOH}$ as compared to women with normal pregnancy. OR confirmed such co-infection type and BOH development.

Conclusion: TORCH complex agent's co infections were a risk factor that increased development of BOH.

Keywords: TORCH; IgG; IgM; Toxoplasma; Rubella; CMV; HSV; BOH; Co-Infection

\section{Introduction}

Infectious pathogens are one of the causal agents for secondary immunosupression and acquired immunosupression due to pathogens is primarily caused by viruses that invade the cellular compartment of the immune system [1]. Viruses induced immunosupression by a variety of mechanisms [2]. Immunosupression may results from direct effects of viral replication on lymphocytes functions and this effect may be selective on 


\section{Virology \& Immunology Journal}

subtypes or all classes of lymphocytes [2]. In addition, virus infected cells release soluble materials which may lead to immunosupression or macrophage function disturbances due to direct viral infection to macrophage. Furthermore, viral infections may trigger an imbalance in immune regulation characterized by over activity of suppressor cells [2].

During natural rubella infection, at the time of rash appearance, mitogens activation of lymphocytes was reduced. In addition, rubella infections lead to a reduction in helper lymphocyte and increase in suppressor cells number [3]. These mechanisms may act collectively in a synergistic fashion to induce immunosupression. Cytomegalovirus (CMV) is associated with sustained general immunosupression of the host $[4,5]$. Reported studies indicated that TNF dependent release of arachidonic acid and PGE2 contribute to CMV-induced immunosupression [5]. Furthermore, CMV interferes with signal transduction pathways in T-cell [6].

Toxoplasma gondii infection may induce immunosupression through immunomodulation of the immune response [7]. Under the influence of INF- $\gamma$, nitrogen monoxide is capable of reducing lymphocyte proliferation, the same is true for IL-10 [8,9]. Toxoplasma proteins, such as surface antigen 1 and micron me proteins directly control the above changes [10]. However, these immunosupression is only exerted on the splenic and mesenteric lymphocytes [11]. Reduction of the production of IL-12 by dendritic cells and increase in the production of IL-10 is reported to occur during course of toxoplasma infection [12]. These immunosuppressant mechanisms induced during toxoplasma infection, prevent the development of type 1 immunopathological phenomena [13]. Thus ensure the survival of the host, but also that of toxoplasma gondii [7]. Thus we hypothesized that infection with either one of Toxoplasma gondii, CMV or rubella may trigger the infection with others. The aim of the present study was to determine whether coinfection of TORCH complex agents increased the development of bad obstetric outcome.

\section{Patients and Methods}

\section{Study design}

This descriptive case-control study, the study population was women (Pregnant or Non pregnant) with a bad obstetric history, are with childbearing age and they recruited from Kirkuk General Hospital and Primary Health care Centres located in Kirkuk Governorate. In addition, one of the study population groups is to be recruited from pregnant women who are in labor to select the group of pregnant with risky outcomes.

\section{Inclusion \& Exclusion criteria}

The study population was recruited using a predesigned, pretested schedule of inclusion and exclusion criteria. Other causes of foetal lose should be excluded by performing clinical examination and laboratory investigations. All subjects included in the study were interviewed to gather demographic and clinical information.

\section{Ethical approval}

The study design was approved by the ethical committee of Tikrit University College of Medicine and informed consent was taken from each women included in the study.

\section{Study Population}

The target number recruited for each group was 150 women. However, the total number of women included in the study was 538, of them 293 (54.5\%) were with BOH, and $245(45.5 \%)$ were with normal pregnancy history. In the BOH group, 144 (49.1\%) women were pregnant, while the corresponding value in the normal pregnancy group was 117 (47.7\%).

\section{Grouping of patients}

Group 1: Pregnant women with age range of 15-48 years, and normal pregnancy (without risk factors).

Group 2: Non pregnant women with age range of $15-48$ years, and previous normal pregnancy.

Group 3: Pregnant women with Risk factor (BOH) depending on their previous pregnancy and /or delivery outcome which include pregnancy loss, intrauterine deaths, preterm deliveries and intrauterine growth retardation. Their age range from 15 - 48 years.

Group 4: Non- pregnant women with Risk factor depending on their previous pregnancy and /or delivery outcome which include pregnancy loss, intrauterine deaths, preterm deliveries and intrauterine growth retardation. Their age range from 15 - 48 years.

\section{Methods}

ELISA was used for determination of IgM and IgG for Toxoplasma, Rubella, CMV, and HSV-2 and the test was performed according to manufacturer instructions. The kit purchased from BioCheck, Inc, 323 Vintage Park Dr, Foster City, CA 94404. The test results read by Microwell reader at $450 \mathrm{~nm}$ on an ELISA reader. 


\section{Virology \& Immunology Journal}

\section{Analysis of Data}

Chi squared test used for comparison between the groups and was employed using the SPSS (Version 16). If the sample size in $\mathrm{BOH}$ group not reach the targeted number Power Analysis are to be performed to determine the accuracy of findings. The study finding data are presented as frequency \pm SD and 95\% Confidence Interval. Bivariate Regression Line Analysis to calculate Odd Ratio for determination of association between two variables. The determinants for Toxoplasma, Rubella, and CMV infection are determined by calculation of Odd Ratio using Logistic Regression Line Analysis. Confounding factors such as age, socio-economic status, e.t.c are standardized when serological determinants are calculated.

\section{Results}

There was a significant frequency difference $\left(X^{2}=65.1\right.$ ANOVA; $\mathrm{P}=0.000$ ) in seroprevalence of $\mathrm{T}$. gondii, rubella and $\mathrm{CMV}$ IgG as indication of co-infection between pregnant $\mathrm{BOH}$, non pregnant $\mathrm{BOH}$, pregnant normal, and non-pregnant normal. In addition, Toxoplasma, rubella and CMV co-infections were significantly lower $\left(\mathrm{X}^{2}=11.5\right.$, $\mathrm{P}=0.001)$ in women with $\mathrm{BOH}(18.8 \%)$ as compared to that with normal pregnancy (31.4\%). OR confirm such association $(\mathrm{OR}=1.9833, \mathrm{P}=0.0006)$, (Tables 1 \& 2).

Rubella and CMV co-infections was significantly higher $\left(\mathrm{X}^{2}=23.3, \mathrm{P}=0.000\right)$ in women with $\mathrm{BOH}(87.7 \%)$ as compared to women with normal pregnancy (71\%). OR confirmed such co-infection type and $\mathrm{BOH}$ development $(\mathrm{OR}=2.913, \mathrm{P}<0.0001)$, (Tables 1 \& 2).

\section{Discussion}

The present study indicated a significant frequency difference $\left(\mathrm{X}^{2}=65.1\right.$-ANOVA; $\left.\mathrm{P}=0.000\right)$ in seroprevalence of $\mathrm{T}$. gondii, rubella and CMV IgG as indication of coinfection between Pregnant $\mathrm{BOH}$, No pregnant $\mathrm{BOH}$, Pregnant normal, and non-pregnant normal. In addition, Toxoplasma, rubella and CMV co-infections were significantly lower $\left(\mathrm{X}^{2}=11.5, \mathrm{P}=0.001\right)$ in women with $\mathrm{BOH}(18.8 \%)$ as compared to that with normal pregnancy (31.4\%). OR calculation confirm such association $(\mathrm{OR}=1.9833, \mathrm{P}=0.0006)$. Higher co-infection in women with normal pregnancy was due to influence of $\mathrm{T}$. gondii high rate of seropositivity in our study population. This is confirmed by the calculation of OR which is lower than 1.00 indicating such influence $(\mathrm{P}=0.009)$, and the difference between the two group was not significantly varied. In addition, seropositive patients may be more prone to get CMV and rubella co-infections.
As reported previously, in subject with $T$. gondii infections there was higher rate of association with CMV (1.94 times than in seronegative) HSV-1 (1.35 times than in seronegative) infections [14]. Our findings indicated that $\mathrm{T}$ gondii IgG antibodies was positively associated with the presence of rubella IgG, and CMV IgG, but not HSV-2.

Transmission of CMV was promoted by poor socioeconomic conditions that are characterized by overcrowding and lack of personal hygiene, and children placing in day care [15]. Reported studies indicated an association between $T$. gondii infection and low socioeconomic status, which may explain why individual with CMV seropositive were likely seropositive for toxoplasma [14,16-19]. Furthermore, rubella and CMV coinfections were significantly more predominant $\left(\mathrm{X}^{2}=23.3\right.$, $\mathrm{P}=0.000)$ in women with $\mathrm{BOH}(87.7 \%)$ than in that with normal pregnancy (71\%). OR confirmed the association between rubella and CMV co-infection and $\mathrm{BOH}$ $(\mathrm{OR}=2.913, \mathrm{P}=<0.0001)$.

Co-infections with viruses in subject seropositive for $T$. gondii would worsen more the patient's situation. We investigate co-infection in our study population to determine the impact of toxoplasmosis and selection of proper treatment approach $[14,20]$. In the present study, we also look for co-infections and found accompanying acute CMV, and rubella but not HSV-2 with T. gondii infections.

The immune response to infectious agents is a complicated phenomenon usually characterised by rapid production of specific antibodies and activation of cell mediated immunity. On the other hand, suppression of the immune system has been shown to occur in many viral infections, which in turn can expose the individual to diseases caused by other infectious agents. Two previous studies in Qatar (T. gondii, CMV and HSV-1) and Turkey (CMV, HCV, EBV and rubella) reported co-infections $[14,20]$ in childbearing age women. The present and these two studies pointed out new trends in infections in women during pregnancy, which may be able to lead to more complicated pregnancy outcomes. Future, larger scale study taking in consideration more confounding factors and variables and its correlation to biochemical markers is warranted.

The original finding of von Pirquet was delayed cutaneous reactivity to tuberculin during measles virus infection [21]. Reported studies observed immunological depression during infectious mononucleosis, varicella, measles, and CMV infections, and after rubella vaccination 


\section{Virology \& Immunology Journal}

[22-25]. The definite reason for the suppression as well as the general regulatory events of the immune response is still not well understood. Cytomegalovirus infection induces immunosuppression, and subsequently associated with high incidence of microbial infections $[26,27]$. This immunosuppressive phenomenon may be a character of infection with toxoplasma and rubella.

Acute CMV infection is associated with sustained general immunosuppressant activity to the host as demonstrated in CMV mononucleosis with impaired cell mediated immunity [28]. The peripheral blood lymphocytes from these patients exhibit a diminished proliferative response to mitogens and herpes virus antigens with a reversal of CD4/CD8 cell ratio. This has been attributed to an increase in CD8 positive cells [28]. CMV infected monocytes (MO) in vitro were reported to be more suppressive when compared to uninfected MO for autologus lymphocyte responses to concanvalin A [29]. It has been suggested that in vivo MO may act as a reservoir for CMV replication and dissemination [30].

The mechanism(s) underlying CMV-mediated immunosupression is unclear. CMV infection in vitro has been shown to affect cellular activation pathways of human fibroblasts. CMV was reported to induce the hydrolysis of phosphatidyl inositol 4, 5 biphosphate $\left(\mathrm{PIP}_{2}\right), \mathrm{Ca}{ }^{2+}$ influx, and an increase in intracellular free $\mathrm{Ca}^{2+}$, as well as increased cellular levels of cAMP and cGMP, and arachidonic acid (AA) metabolism [31-33]. More recently, it has been reported that CMV affects transmembrane signaling pathways in CD4-positive Tlymphocytes. CMV enhanced HIV replication in T cells via a cAMP and protein kinase C-dependent pathway [6].
In a previous study, it is demonstrated that CMV infection of human MO in vitro was associated with enhanced TNFa production that induced the release of AA and $\mathrm{PGE}_{2}$. The latter inhibited T-cell activity, which might partially account for the immunosuppressive effects characteristic of CMV. The phase of CMV expression responsible for the induction of AA release was consistent with the conditions associated with CMV immediate early gene expression [5]. Furthermore, CMV encoded Interleukin-10 has ability to induce immunosupression, CMV evade of immune system, proinflammatory cytokines synthesis reduction [4]. In addition, major histocompatibility complex (MHC) class I and II molecules expression was reduced, while in contrast, non-classical MHC allele HLA-G and subvert NK cell activity expression were increased [4]. All the above mechanisms could explain the induction of immunosupression by CMV infection.

Rubella infections decreased lymphocyte blast transformation, capable of infecting human leukocytes, and consequences of regulatory T-cells activity [34]. In addition, Hyypia, et al. suggested that in rubella infection, there was suppressor to helper T cells imbalance which is due to increased proportion of $\mathrm{T}$ cells with suppressor/cytotoxic phenotype and decreased proportion of cells with helper/inducer phenotypes [3]. The above mentioned mechanisms that induced following CMV and rubella infections tend to accentuate the immunosupression and may lead to co-infection or reactivation of $T$. gondii.

In conclusion, TORCH complex agent's coinfections were a risk factor that increased development of abnormal pregnancy outcomes.

\begin{tabular}{|c|c|c|c|c|c|}
\hline \multirow{2}{*}{ Variable/ or Group } & \multicolumn{4}{|c|}{ Type of co- infection trends } \\
\cline { 2 - 6 } & $\begin{array}{c}\text { Toxoplasma-IgG } \\
\text { Rubella - IgG } \\
\text { CMV - IgG } \\
\text { No. +/Total }\end{array}$ & $\begin{array}{c}\text { Rubella - IgG } \\
\text { CMV - IgG } \\
\text { No. +/Total }\end{array}$ & $\begin{array}{c}\text { Toxoplasma-IgM } \\
\text { CMV - IgM } \\
\text { No. +/Total }\end{array}$ & \multicolumn{3}{c|}{$\begin{array}{c}\text { Rubella - IgM } \\
\text { CMV - IgM } \\
\text { No. +/Total }\end{array}$} \\
\hline BOH Pregnant & $20 / 144$ & $128 / 144$ & $4 / 144$ & $4 / 144$ & \\
\hline BOH Non- pregnant & $35 / 149$ & $129 / 149$ & $0 / 149$ & $0 / 149$ & \\
\hline Normal pregnant & $13 / 117$ & $78 / 117$ & $0 / 117$ & $0 / 117$ & \\
\hline Normal non-pregnant & $64 / 128$ & $96 / 128$ & $0 / 18$ & $1 / 128$ & \\
\hline Chi Square [ANOVA] & 65.1 & 11 & Undefined & 7.95 & \\
\hline P value & 0 & 0.012 & Undefined & 0.047 & \\
\hline All BOH & $55 / 293$ & $257 / 293$ & $4 / 293$ & $4 / 293$ & \\
\hline All Normal Pregnancy & $77 / 245$ & $174 / 245$ & $0 / 245$ & $1 / 245$ & \\
\hline Chi square & 11.5 & 23.3 & 3.37 & 1.33 & \\
\hline P value & 0.001 & 0 & 0.06 & NS & \\
\hline
\end{tabular}

Table 1: Frequency of TORCH complex agent's co-infections trends. 


\section{Virology \& Immunology Journal}

\begin{tabular}{|c|c|c|}
\hline Co- infection Trends & Odd Ratio [95\% Confidence Interval] & P value \\
\hline $\begin{array}{c}\text { Toxoplasma - IgG } \\
\text { Rubella - IgG } \\
\text { CMV - IgG }\end{array}$ & $1.9833[1.3316-2.9541]$ & $\mathbf{0 . 0 0 0 6}$ \\
\hline $\begin{array}{c}\text { Rubella - IgG } \\
\text { CMV - IgG }\end{array}$ & $2.913[1.8671-4.5448]$ & $<\mathbf{0 . 0 0 0 1}$ \\
\hline
\end{tabular}

Table 2: Odd ratio of Co-infection trends in TORCH complex of IgG.

\section{References}

1. Elfaki MG, Al-Hokail AA, Kambal AM (2012) Microbial immunosupression. Immunosuppression- role in Health and Diseases pp: 215-224.

2. Rouse BT, Horohov DW (1986) Immunosuppression on viral infections. Rev Infect Dis 8: 850-873.

3. Hyypia T, Eskola J, Laine M, Meurman O (1984) B-Cell Function In Vitro During Rubella Infection. Infect Immun 43(2): 589-592.

4. Spencer JV, Lockridge KM, Barry PA, Lin G, Tsang M, et al. (2002) Potent Immunosuppressive Activities of Cytomegalovirus- Encoded Interleukin-10. J Virol 76(3): 1285-1292.

5. Nokta MA, Hassan MI, Loesch K, Pollard RB (1996) Human cytomegalovirus-induced immunosuppression. J Clin Invest 97(11): 2635-2641.

6. Hassan MI, Nokta MA, Pollard RB (1993) Involvement of cAMP and protein kinase $\mathrm{C}$ in cytomegalovirus enhancement of human immunodeficiency virus replication. Proc Soc Exp Biol Med 204(2): 216-223.

7. Filisetti D, Candolfi E (2004) Immune response to Toxoplasma gondii. Ann $1^{\text {st }}$ Super Sanita 40(1): 71-80.

8. Candolfi E, Hunter CA, Remington JS (1994) Mitogen and antigen specific proliferation of T cells in murine toxoplasmosis is inhibited by rective nitrogen intermediates. Infect Immun 62(5): 1995-2001.

9. Candolfi E, Hunter CA, Remington JS (1995) Role of gamma interferon and other cytokines in suppression of the spleen cell proliferative response to Concanavaline A and toxoplasma antigen during acute toxoplasmosis. Infect Immun 63(3): 751-756.

10. Neyer LE, Kang H, Remington JS, Suzuki Y (1998) Mesenteric lymph node $\mathrm{T}$ cells but not splenic T cells maintain their proliferative response to concanavalinA following peroral infection with Toxoplasma gondii. Parasite Immunol 20(12): 573-581.
11. Seng S, Nagasawa H, Maki Y, Yokoyama M, Inoue N, et al. (1999) Increased susceptibility to Toxoplasma gondii infection in SAG-1 transgenic mice. Int J Parasitol 29(9): 1433-1436.

12. Reis e Sousa C, Yap G, Schulz O, Rogers N, Schito M, et al. (1999) Paralysis of dendritic cell IL-12 production by microbial products prevents infection-induced immunopathology. Immunity 11(5): 637-647.

13. Mordue DG, Monroy F, La Regina M, Dinarello CA, Sibley LD (2001) Acute toxoplasmosis leads to lethal overproduction of Th1 cytokines. J Immunol 167(8): 4574-4584.

14. Abu-Madi MA, Behnke JM, Dabritz HA (2010) Toxoplasma gondii seropositivity and coinfection with TORCH pathogens in high-risk patients from Qatar. Am J Trop Med Hyg 82(4): 626-633.

15. Dowd JB, Aiello AE, Alley DE (2009) Socioeconomic disparities in the seroprevalence of cytomegalovirus infection in the US population: NHANES III. Epidemiol Infect 137(1): 58-65.

16. Jones JL, Kruszon-Moran D, Wilson M, McQuillan G, Navin T, et al. (2001) Toxoplasma gondii infection in the United States: seroprevalence and risk factors. Am J Epidemiol 154(4): 357-365.

17. Frenkel JK, Hassanein KM, Hassanein RS, Brown E, Thulliez P, et al. (1995) Transmission of Toxoplasma gondii in Panama City, Panama: a five-year prospective cohort study of children, cats, rodents, birds, and soil. Am J Trop Med Hyg 53(5): 458-468.

18. Bahia-Oliveira LM, Jones JL, Azevedo-Silva J, Alves CC, Oréfice F, et al. (2003) Highly endemic waterborne toxoplasmosis in north Rio de Janeiro State, Brazil. Emerg Infect Dis 9(1): 55-62.

19. de Amorim Garcia CA, Oréfice F, de Oliveira Lyra C, Gomes AB, França M, et al. (2004) Socioeconomic conditions as determining factors in the prevalence of systemic and ocular toxoplasmosis in northeastern Brazil. Ophthalmic Epidemiol 11(4): 301-317. 


\section{Virology \& Immunology Journal}

20. Akyar I (2011) Seroprevalence and Coinfections of Toxoplasma gondii in Childbearing Age Women in Turkey. Iranian J Publ Health 40(1): 63-67.

21. von Pirquet PC (1980) Das Verhalten der kutanen TuberkulinReaktion wahrend der Masern. Dtsch Med Wochenschr 34(30): 1297-1300.

22. Arneborn P, Biberfeld G (1983) T-lymphocyte subpopulations in relation to immunosuppression in measles and varicella. Infect Immun 39(1): 29-37.

23. Arneborn P, Biberfeld G, von Stedingk LV (1982) Tlymphocyte subpopulations defined by monoclonal antibodies and 7c receptor binding in relation to immunosuppression in vaccine-induced rubella infection. Acta Pathol Microbiol 90: 163-170.

24. Bertotto A, Gentili F, Vaccaro R (1982) Immunoregulatory T-cells in varicella. $\mathrm{N}$ Engl J Med 307(20): 1271-1272.

25. Mangi RJ, Niederman JC, Kelleher JE Jr, Dwyer JM, Evans AS, et al. (1974) Depression of cell mediated immunity during acute infectious mononucleosis. N Engl J Med 291(22): 1149-1153.

26. Boeckh M (2011) Complications, diagnosis, management, and prevention of CMV infections: current and future. Hematology 2011: 305-309.

27. Boeckh M, Geballe AP (2011) Cytomegalovirus: Pathogen, Paradigm, and Puzzle. J Clin Invest 121(5): 1673-1680.
28. Rinaldo CR Jr, Carney WP, Richter BS, Black PH, Hirsch MS (1980) Mechanisms of immunosuppression in cytomegallo viral mononucleosis. J Infect Dis 141(4): 488-495.

29. Carney WP, Hirsch MS (1981) Mechanisms of immunosuppression in cytomegalovirus mononucleosis. II. Virus-monocyte interactions. J Infect Dis 144(1): 47-54.

30. Schrier RD, Nelson JA, Oldstone MB (1985) Detection of human cytomegalovirus in peripheral blood lymphocytes in a natural infection. Science 230(4729): 1048-1051.

31. Albrecht T, Boldogh I, Fons M, Abubakar S, Deng CZ (1990) Cell activation signals and the pathogenesis of human cytomegalovirus. Intervirology 31(2-4): 6875.

32. Abubakar S, Boldogh I, Albrecht T (1990) Human cytomegalovirus: stimulation of [3H] release from $[3 \mathrm{H}]$-arachidonic acid prelabeled cells. Arch Virol 113(3-4): 255-266.

33. Abubakar S, Boldogh I, Albrecht T (1990) Human cytomegalovirus stimulates Arachidonic acid metabolism through pathways that are affected by inhibitors of phospholipase A2 and protein kinase C. Biochem Biophys Res Commun 166(2): 953-959.

34. Chantler JK, Tingle AJ (1982) Isolation of rubella virus from human lymphocytes after acute natural infection. J Infect Dis 145(5): 673-677. 